OPEN ACCESS

Edited by:

Martin Chalumeau,

Université Paris Descartes, France

Reviewed by:

Anne-Sylvia Sacri,

INSERM U1153 Centre de Recherche Épidémiologie et Statistique, France

Florence Hoogewoud,

Hôpital Ophtalmique

Jules-Gonin, Switzerland

*Correspondence:

Hulya Bukulmez

hxb38@case.edu;

hbukulmez@metrohealth.org

Specialty section:

This article was submitted to

General Pediatrics and Pediatric

Emergency Care

a section of the journal

Frontiers in Pediatrics

Received: 26 September 2019

Accepted: 22 June 2020

Published: 04 August 2020

Citation:

Gullapalli K, Goldzweig O, Nanda K

Chekka R, Berry S and Bukulmez H

(2020) Juvenile Dermatomyositis

(JDM) Complicated by Thrombotic

Thrombocytopenic Purpura (TTP) and

Purtscher's Retinopathy Responsive

to Rituximab: Case Report and

Literature Review.

Front. Pediatr. 8:436

doi: 10.3389/fped.2020.00436

\section{Juvenile Dermatomyositis (JDM) Complicated by Thrombotic Thrombocytopenic Purpura (TTP) and Purtscher's Retinopathy Responsive to Rituximab: Case Report and Literature Review}

\author{
Keerthi Gullapalli ${ }^{1}$, Ofra Goldzweig ${ }^{2}$, Kabita Nanda $^{3}$, Ravi Chekka ${ }^{4}$, Shanail Berry ${ }^{5}$ and \\ Hulya Bukulmez ${ }^{6 *}$
}

${ }^{1}$ Internal Medicine, Sparrow Hospital, Michigan State University, Lansing, MI, United States, ${ }^{2}$ Pediatrics, Kaplan Medical Center, Rehovot, Israel, ${ }^{3}$ Rheumatology, Seattle Children's Hospital, Seattle, WA, United States, ${ }^{4}$ Pediatrics, Pediatric Care Center, Erie, PA, United States, ${ }^{5}$ Pediatrics, Metro Health System, Cleveland, OH, United States, ${ }^{6}$ Division of Pediatric Rheumatology, Department of Pediatrics, MetroHealth Medical Center, CWRU, Cleveland, OH, United States

Juvenile dermatomyositis (JDM) is a multisystem vasculopathy that infrequently presents with acute complications (1). We report here the case of a 12-year-old girl with JDM who developed Thrombotic Thrombocytopenic purpura (TTP) and Purtscher's retinopathy. This is the second pediatric case of JDM with TTP and Purtscher's retinopathy in the literature. The diagnosis of JDM was based on her clinical presentation (fever, myalgia, proximal muscle weakness, characteristic skin rash and elevated muscle enzymes) (2). Despite improvement of rash, fever and weakness with corticosteroids and intravenous Immunoglobulins (IVIG), the patient developed retinopathy, thrombocytopenia, hemolytic anemia, renal failure, and pulmonary edema within 1 week of initial treatment. A clinical diagnosis of TTP and Purtscher's retinopathy was made and her ADAMTS13 activity was found to be low. Regardless of aggressive treatment with pulse steroid therapy, IVIG, plasmapheresis along with multiple infusions of Fresh Frozen plasma (FFP), her condition deteriorated. In view of her worsening condition, she received one dose of Rituximab and within $48 \mathrm{~h}$, her hematological and retinal involvements improved. Rituximab was given at the same dose once weekly thereafter for 4 total doses. Her disease process was halted, and retinopathy improved significantly in $48 \mathrm{~h}$ and continued to gradually improve over 3 weeks of maintenance therapy with cyclosporine, methotrexate, and IVIG and then stabilized. This report documents the association of TTP and Purtscher's retinopathy with JDM, emphasizing that early recognition and prompt treatment with rituximab along with the current standard of care treatment i.e., Vincristine, corticosteroids and plasmapheresis could be of potential benefit in controlling disease activity.

Keywords: juvenile dermatomyositis, TTP, purtscher's retinopathy, ADAMTS13, rituximab, vWF 


\section{BACKGROUND}

JDM is a rare autoimmune multi-system vasculopathy occurring in about 2-4 per Million children per year in the United States with peak onset between 5 and 14 years of age (1). Dermatological and muscle manifestations are most common at presentation. The diagnostic criteria for JDM includes: symmetric weakness of proximal muscles, characteristic dermatological changes (heliotrope discoloration of the eyelids with periorbital edema, and Gottron's papules which are erythematous scaly rash over dorsal aspects of the metacarpophalangeal and proximal interphalangeal joints), elevation in one or more serum skeletal muscle enzymes [creatinine kinase (CK), Aldolase, Aspartate Aminotransferase (AST), Lactate Dehydrogenase $(\mathrm{LDH})$ ], electromyographic demonstration of myopathy, muscle necrosis, perifascicular atrophy and inflammation on muscle biopsy (2). The pathogenesis of the disease includes an autoimmune angiopathy with cell mediated immunity to muscle antigens. The cellular infiltrate includes a large component of plasmacytoid dendritic cells. Several autoantibodies are associated with JDM including both myositis-specific and myositis associated (2). Furthermore, von Willebrand factor (vWF), an endothelial bound clotting factor, is found to be elevated during JDM activity due to the inflammation and ongoing autoimmune vascular injury (3). It is unknown whether vWF has a role in triggering TTP. Although rare, adult onset dermatomyositis and TTP has been reported previously to be seen concurrently (4-10). There has been one report of a JDM patient from France that developed TTP and Purtscher's retinopathy (11).

TTP is a thrombotic microangiopathy with an annual incidence of 3-11 cases per million, with about $5-10 \%$ of the cases occurring in children (12). The disease is characterized by formation of microthrombi in multiple organ systems causing sequelae of hemolytic anemia, thrombocytopenia, renal injury, neurological changes and multiorgan dysfunction (12). The basic pathogenesis results from an imbalance between Ultra Large von Willebrand Factor (ULvWF) multimers and ADAMTS13 (a disintegrin; a metalloprotease with 13 thrombospondin type 1 repeats) either secondary to decreased production or the formation of antibodies against ADAMTS13 (12). ADAMTS13 is a member of proteases with specific features involved in cleaving vWF multimers. ULvWF multimers are suggested to be cleaved by ADAMTS-13 at position $842 \mathrm{Tyr}$ - $843 \mathrm{Met}$ preventing them to become multimers (12). The vascular thrombi are caused by intravascular accumulation of large multimers of vWF. Abnormalities of vWF protease activity are not restricted to patients with the diagnosis of TTP (13). TTP is a known complication of several autoimmune and inflammatory diseases including systemic lupus erythematosus (SLE) and dermatomyositis (DM). It is speculated that autoimmune activity with excess B-cell response and IgG antibodies to ADAMTS13 are key triggers in the development of secondary TTP in SLE (14). Thus, there has been a debate whether immune suppressive therapies that suppress B cell activity might be beneficial in autoimmune disease associated TTP treatment (15). Rituximab is an anti-CD20 antibody and has been found to be effective in autoantibody mediated autoimmune diseases including, autoimmune hemolytic anemia, thrombocytopenia, cold agglutinin disease (16) and acquired factor VIII inhibitors (17). Rituximab depletes the CD-20 positive B cells using antibody dependent cellular cytotoxicity and complement mediated lysis. Depletion of peripheral B cells might interrupt the ongoing humoral autoimmune response providing a rationale for its use in TTP (18). Although Rituximab treatment for TTP has been reported previously (5), children with JDM associated TTP who responded to rituximab have not been reported before.

Purtscher's retinopathy is a hemorrhagic and vaso-occlusive vasculopathy which was originally described as a syndrome of sudden blindness after head trauma but later described with pancreatitis and collagen vascular diseases (19). It is characterized by appearance of retinal whitening and hemorrhage and retinal edema predominantly around the optic disc (19). It is speculated to be caused by complement activation after acute crushing injuries to head or thorax (19). Here we describe a case, which presented with JDM and developed TTP, end organ damage and Purtscher's retinopathy that has shown a dramatic response to B cell ablating therapy with rituximab.

\section{CASE PRESENTATION}

A previously healthy, athletic 12 -year-old girl presented with a 2-week history of headache, febrile myalgia, muscle weakness, and rash (not shown). On examination, she had tenderness and weakness of proximal muscles of legs and arms, heliotrope rash, Gottron's papules, erythematous rash on trunk and upper arms (Shawl sign), and mild swelling of bilateral knees and ankles. Laboratory work-up demonstrated elevated muscle enzymes as shown in Table 1. A subsequent MRI of bilateral quadriceps demonstrated increased scattered heterogeneous T2 signal intensity indicating inflammation (not shown). The patient was diagnosed with JDM per Bohan and Peter criteria (2). On Eye examination, patient had 20/20 vision and fundus was normal.

Patient was hospitalized for pulse IV methylprednisolone (30 $\mathrm{mg} / \mathrm{kg} /$ day $)$ and one dose of IVIG $(1 \mathrm{~g} / \mathrm{kg} /$ day $)$ treatment. Her laboratory values upon first admission are shown in Table $\mathbf{1}$. C-ANCA P-ANCA, Coombs test, anti-platelet antibodies, and ANA were negative. Weakness and rash improved significantly after treatment and she was discharged with oral prednisone $(2 \mathrm{mg} / \mathrm{kg} /$ day $)$ with taper in 4 weeks, methotrexate (20 $\mathrm{mg} / \mathrm{m} 2 /$ week), folic acid (1 $\mathrm{mg}$ daily), and naproxen (20 mg/kg/day).

Despite rapid fever resolution and improvement of myalgia and muscle weakness, the patient presented to Emergency department approximately 1 week later with blurry vision and severe headache. The patient was admitted to Pediatric Intensive Care Unit (PICU). Course of her hospital stay, and medications given are as follows:

Day 1: Labs demonstrated exacerbation of JDM with elevated muscle enzymes, elevated acute phase reactants, anemia, thrombocytopenia, and renal failure as shown in Table 1. Peripheral blood smear showed schistocytosis. Treatment 
TABLE 1 | Key laboratory values upon 1st admission and readmission to PICU.

\begin{tabular}{|c|c|c|c|c|c|c|}
\hline Test & Normal & $\begin{array}{l}\text { 1st } \\
\text { admission }\end{array}$ & $\begin{array}{l}\text { PICU } \\
\text { day1 }\end{array}$ & $\begin{array}{l}\text { PICU } \\
\text { day2 }\end{array}$ & $\begin{array}{l}\text { PICU } \\
\text { day3 }\end{array}$ & $\begin{array}{l}\text { PICU } \\
\text { day6 }\end{array}$ \\
\hline Aldolase (U/L) & $1-7.5$ & 37 & 67 & - & - & - \\
\hline LDH (U/L) & 110-295 & 802 & 2,543 & - & - & - \\
\hline CK (U/L) & $30-170$ & 69 & 61 & - & - & - \\
\hline Creatinine (mg/dl) & $0.7-1.3$ & 1 & 2.9 & 3.3 & 4.4 & 5.3 \\
\hline BUN (mg/dl) & $8-20$ & 23 & 66 & 76 & 94 & 83 \\
\hline $\operatorname{VWF}(\%)$ & $55-200$ & 418 & 382 & - & - & - \\
\hline AST (U/L) & $8-40$ & 15 & 92 & - & - & - \\
\hline ALT (U/L) & $8-40$ & 29 & 68 & - & - & - \\
\hline ADAMTS13 (\%) & $50-160$ & - & 64 & - & - & - \\
\hline Factor VIII (\%) & $50-150$ & 293.9 & - & - & - & - \\
\hline $\begin{array}{l}\text { Ristocetin } \\
\text { cofactor (\%) }\end{array}$ & 50-200 & 314 & - & - & - & - \\
\hline Hemoglobin (g/dl) & $12-16$ & 11.6 & 8.4 & 6.4 & 7 & 10.9 \\
\hline $\begin{array}{l}\text { Platelets (per } \\
\mathrm{mm}^{3} \text { ) }\end{array}$ & $\begin{array}{l}150,000- \\
400,000\end{array}$ & 301,000 & 61,000 & 34,000 & - & 15,000 \\
\hline PT (s) & $11-15$ & - & 13.5 & - & - & - \\
\hline $\mathrm{PTT}(\mathrm{s})$ & $25-40$ & - & 20.6 & - & - & - \\
\hline INR & $<1.1$ & - & 1.2 & - & - & - \\
\hline Fibrinogen (ug/dl) & $150-400$ & - & 350 & - & - & - \\
\hline
\end{tabular}

initiated with a pulse of IV methylprednisolone $(30 \mathrm{mg} / \mathrm{kg} / \mathrm{d})$ and subsequently plasmapheresis was initiated. Patient also developed pulmonary edema which was managed with inhalation of bronchodilators, non-invasive ventilation and aggressive diuresis.

Day 2: Anemia, renal injury, and thrombocytopenia worsened (Table 1). Plasmapheresis was repeated, followed by FFP and another pulse of IV methylprednisolone $(30 \mathrm{mg} / \mathrm{kg} / \mathrm{d})$.

Day 3: Seizures developed, and she received Lorazepam $2 \mathrm{mg}$ initially and then placed on Fosphenytoin $(20 \mathrm{mg} / \mathrm{kg} / \mathrm{d})$. With the presence of renal injury, seizures, thrombocytopenia, hemolytic anemia, and schistocytes on peripheral smear, she was diagnosed with TTP. Hemolytic anemia and renal failure continued to worsen (Table 1). Another IV pulse methylprednisolone (30 $\mathrm{mg} / \mathrm{kg} / \mathrm{d}$ ) dose was given and 2 volumes plasmapheresis were exchanged. Hemodialysis was performed and was given oneunit packed RBCs. Ophthalmologic examination demonstrated retinal perfusion abnormalities on angiography, whitening, Putscher flecken or cotton wool spots as shown in Figure 1. Patient diagnosed with Purtscher's retinopathy. No treatment was suggested by ophthalmology except for targeted therapy to underlying autoimmune disease. Patient was found to be homozygous for MTHFR 1298 and PAI-1 on a thrombophilia DNA assay panel and had no mutations on Factor $V$ Leiden, Prothrombin 20210A, MTHFR 677, or Factor XIII V34L alleles.

Days 4: Renal injury, hemolytic anemia, and thrombocytopenia persisted. She received 2 cycles of plasmapheresis with FFP replacement, 2 cycles of hemodialysis, and two more methylprednisolone pulses.

Day 5: Vincristine $1 \mathrm{mg}$ and IVIG $1 \mathrm{~g} / \mathrm{kg} / \mathrm{d}$ were given, no improvement was observed.
Day 6: Patients condition continued to worsen. B cell ablating treatment with rituximab $375 \mathrm{mg} / \mathrm{m} 2 /$ dose was initiated. She also continued to have hemodialysis (3 times a week), plasmapheresis (daily) with FFP, IVIG and IV methylprednisolone pulses.

After Rituximab treatment within $48 \mathrm{~h}$ patient's platelets $(103,000 / \mathrm{L})$ increased although renal injury persisted until hospital day 9. Her retinopathy improved significantly within $48 \mathrm{~h}$ of Rituximab treatment. Hemodialysis was discontinued on hospital day 9 due to significant improvement in renal function [BUN (39 mg/dL) and Creatinine $(2.6 \mathrm{mg} / \mathrm{dL})$ ]. Patient continued to have 1 volume plasmapheresis/day until hospital day 11 with only two subsequent single volume plasmaphereses on hospital day 14 and 17. Subsequently, she received 4 total infusions of Rituximab $(350 \mathrm{mg} / \mathrm{m} 2 / \mathrm{d})$ once weekly during her PICU stay (Figure 2). Her disease process was halted, and her condition continued to improve progressively. Figure 2 demonstrates the platelet trend in relation to Rituximab treatment.

On day 25, the patient was discharged home on Gabapentin and Methadone for pain, citalopram, Amlodipine, Atenolol, Levetiracetam, Phenytoin, and Granisetron, and was scheduled for regular outpatient IVIG infusions to maintain remission. For the following 2 years her retinopathy was followed up closely by a retina specialist and was observed to be normal while every 3 weeks IVIG treatments were continued.

Patient has been followed up by pediatric rheumatology till she turned 18 and her current condition is stable. She is attending school full time and continues to competitively swim. She can read using a magnifier and except for her ocular nerve atrophy the retinal lesions are all reported to be improved. She is being followed regularly by ophthalmology in her annual appointments.

\section{LITERATURE REVIEW AND DISCUSSION}

In patients with DM occurrence of TTP is rare. We identified 9 cases of adult onset DM that subsequently developed TTP between 1985 and December 2018 (Table 2) (4-10). In all 9 previously published cases the mean age at TTP onset was 56 years, more prevalent in females. The interval from onset of DM to development of TTP was variable ranging from 1 week to several months. In terms of treatment, 7 out of 9 reported cases were given glucocorticoids and plasmapheresis was done in 7 . Only 3 of 9 cases (33\%) improved and survived. Only 1 case received Rituximab on day 19 but died due to septic shock on day 158 (5). The major cause of death in most cases was septic shock and multiorgan failure. Our patient received Rituximab early in course of disease (day 6) and started improvement within $48 \mathrm{~h}$. We found only one adult DM patient who developed Purtscher's retinopathy (20). In JDM, there has been 1 case reported in France that developed TTP and Purtscher's retinopathy (11). Early IV corticosteroids with plasmapheresis improved the retinal findings back to normal in 6 months in that patient (11).

Our patient's history of JDM with subsequent onset of TTP makes her one of the youngest patients reported to have developed both illnesses. Although both TTP and adult onset 

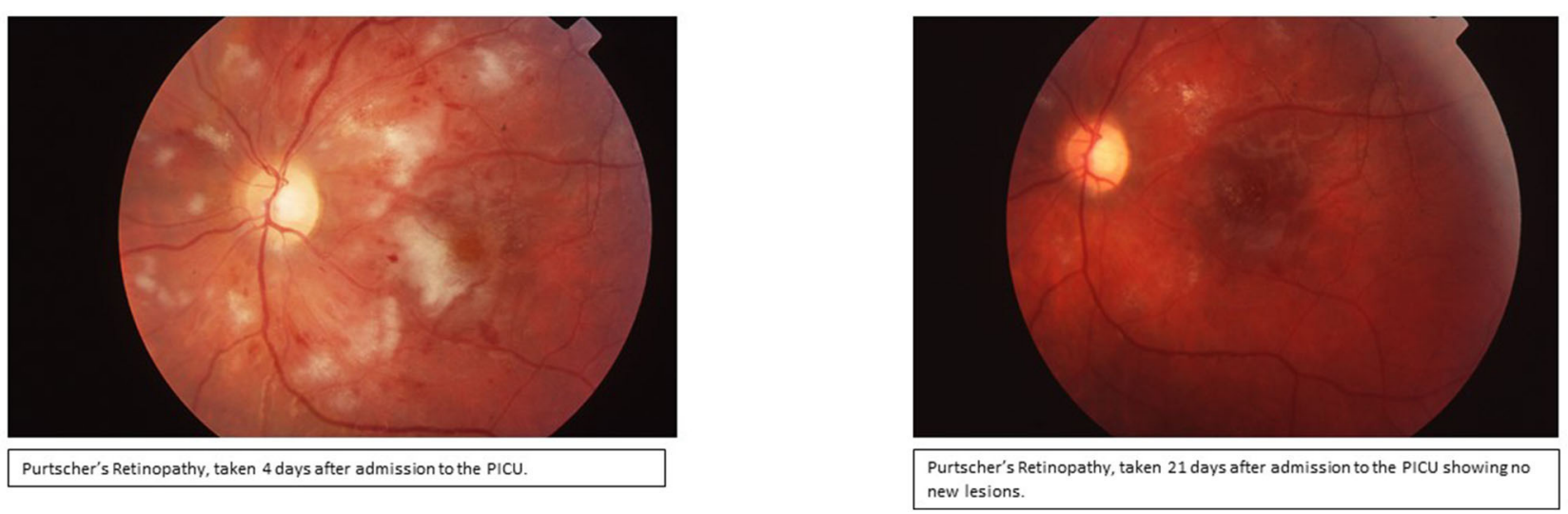

FIGURE 1 | Ophthalmologic examination of fundus demonstrating confluent cotton wool spots around optic disc indicating Purtscher's retinopathy.

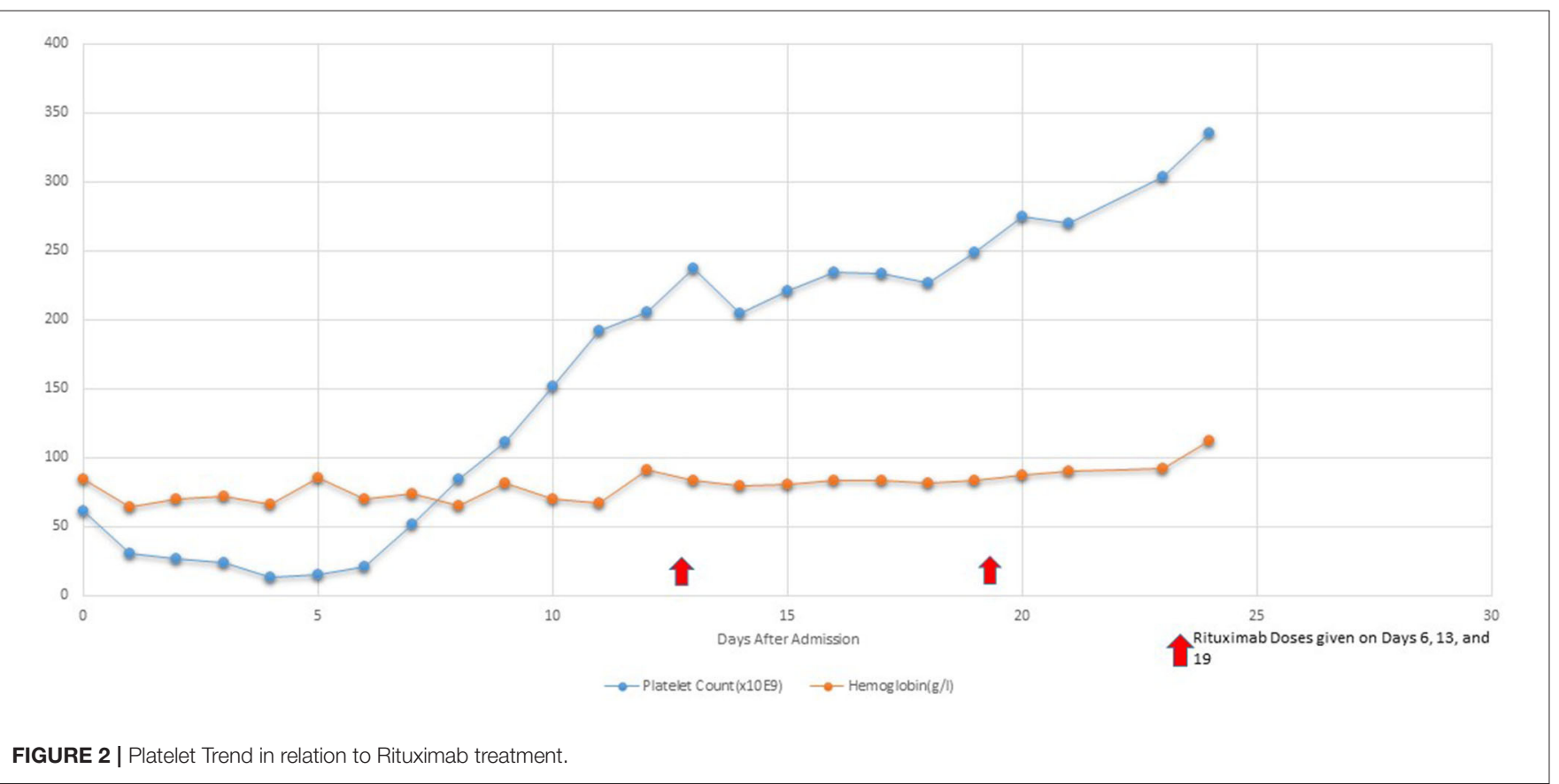

DM have been reported, a firm understanding of the relationship between the two disorders is not well-understood.

The most plausible explanation of DM followed by TTP is that excessive autoimmune activity due to $\mathrm{B}$ cells results in elevated amounts of vWF in the intravascular compartment which makes ultra large multimers and deposits on the vasculature. In addition, IgG autoantibodies are also produced toward ADAMTS-13 and decrease the cleavage of the vWF (14). Thus, during active disease, autoimmunity causes an imbalance between the vWF and ADAMTS-13 activity and triggers TTP onset.

In the present case with JDM while the immunoglobulin levels were high during the initial phase of the disease (not shown), ADAMTS-13 activity level was found to be low. Thus, we speculate that in our patient, ADAMTS-13 activity was not sufficient to cleave the elevated vWF during her active disease. Till date, a single optimal treatment approach has not been identified. Some of the most effective treatments include plasmapheresis alone or in combination with corticosteroids, vincristine, high doses of immunoglobulin. Splenectomy is the treatment option of last resort. IVIG is accepted as an effective treatment in JDM, particularly in those patients with severe vasculopathy (21). In our patient, the deterioration of her condition despite steroids, IVIG, vincristine, methotrexate, plasmapheresis, hemodialysis lead us to use Rituximab along with IVIG which improved her condition within $48 \mathrm{~h}$. It is important to note that this B cell ablation therapy, which depleted immunoglobulin production and decreased the autoantibody production, halted the TTP process and has been successful in controlling the end organ damage in our case with JDM and TTP. Thus, we speculate that 
TABLE 2 | Treatment and outcome of previously reported patients based on literature review.

\begin{tabular}{|c|c|c|c|c|c|}
\hline & Author & Year Age & Treatment & Outcome & References \\
\hline 1. & Malik et al. & 2018 27/F & $\begin{array}{l}\text { Plasmapheresis } \\
\text { only }\end{array}$ & Improved & (4) \\
\hline 2. & Yamada et al. & 2008 69/F & $\begin{array}{l}\text { Methylprednisolone } \\
\text { (mPSL), Tac, } \\
\text { cyclophosphomide, } \\
\text { IVIG, } \\
\text { plasmapheresis }\end{array}$ & $\begin{array}{l}\text { Improved on } \\
\text { day } 115\end{array}$ & (5) \\
\hline 3. & Yamada et al. & 2014 70/M & $\begin{array}{l}\text { mPSL, IVIG, } \\
\text { rituximab (day 19), } \\
\text { plasmapheresis }\end{array}$ & $\begin{array}{l}\text { Died on day } \\
158 \text { due to } \\
\text { septic shock }\end{array}$ & (5) \\
\hline 4. & Yamada et al. & 1996 65/F & $\begin{array}{l}\text { Cyclosporine, IVIG, } \\
\text { PSL, } \\
\text { plasmapheresis }\end{array}$ & $\begin{array}{l}\text { Died on day } 74 \\
\text { due to septic } \\
\text { shock }\end{array}$ & (5) \\
\hline 5. & Saito et al. & 1993 42/M & $\begin{array}{l}\text { IVIG, vincristine, } \\
\text { corticosteroids, } \\
\text { dextran, } \\
\text { plasmapheresis }\end{array}$ & Improved & (6) \\
\hline \multirow[t]{2}{*}{6.} & Miyaoka et al. & 1997 60/M & $\begin{array}{l}\text { Plasmapheresis, } \\
\text { mPSL, IVIG, } \\
\text { antiplatelet therapy }\end{array}$ & $\begin{array}{l}\text { Died on day } 17 \\
\text { due to MOF. }\end{array}$ & (7) \\
\hline & Shoda et al. & $200957 / M$ & mPSL & $\begin{array}{l}\text { Died on day } 13 \\
\text { due to } \\
\text { respiratory } \\
\text { failure }\end{array}$ & (8) \\
\hline 8. & $\begin{array}{l}\text { Sawdyk and } \\
\text { Jundt }\end{array}$ & 1985 65/F & $\begin{array}{l}\text { mPSL, } \\
\text { plasmapheresis, } \\
\text { antiplatelet therapy }\end{array}$ & $\begin{array}{l}\text { Died on day } 11 \\
\text { due to } \\
\text { pneumonia }\end{array}$ & (9) \\
\hline 9. & $\begin{array}{l}\text { Knox- } \\
\text { Macaulay } \\
\text { et al. }\end{array}$ & 2004 48/F & mPSL, IVIG & $\begin{array}{l}\text { Died } \\
\text { immediately }\end{array}$ & (10) \\
\hline 10. & $\begin{array}{l}\text { Bader- } \\
\text { Meunier } \\
\text { et al. }\end{array}$ & 2012 7/M & $\begin{array}{l}\text { PSL and } \\
\text { plasmapheresis }\end{array}$ & Improved & $(11)$ \\
\hline
\end{tabular}

ongoing production of autoantibodies due to activated B cell function were primarily responsible for the TTP etiology.

Another pleasing outcome in our case was the improvement of Purtscher's retinopathy, despite what was predicted, during the PICU stay. In our patient, we speculate that retinopathy is a result of retinal vascular involvement resulting from TTP. IVIG has been suggested to be helpful in JDM vasculopathy and skin manifestations of JDM (21). IVIG might have been useful treating the retinal vascular damage in our case proving its value in treatment of microangiopathic end organ damage secondary to TTP. Thus, it is important to note that in retinopathy secondary to JDM with or without associated TTP, addition of IVIG to other chemotherapy may enhance the regeneration process. Future studies are needed to provide further proof of concept.

Physicians should keep in mind that TTP and/or Purtscher's retinopathy occasionally arise as serious complication of JDM as well as other autoimmune diseases. Furthermore, when VWF levels are found elevated, studying ADAMTS-13 activity might predict the microangiopathic thrombus development in JDM. Thus, anyone presenting with typical manifestations of JDM and clinical features suggesting TTP should be further investigated and treatment with combination of rituximab and IVIG in early stages of TTP needs to be considered in cases refractory to the standard of care.

In conclusion, we presented a very rare case of a patient with JDM with TTP and Purtscher's retinopathy. This case is important to discuss since it showed us the additive effect of Rituximab treatment in halting TTP process in JDM, and the successful improvement in Purtscher's retinopathy. Additionally, our review also indicated that the improvement of retinopathy in the presented case has been significantly shorter than any other reported.

\section{DATA AVAILABILITY STATEMENT}

All relevant data is contained within the article. Furthermore, all data supporting the conclusions of this article are available by the authors, without undue reservation, to any qualified researcher.

\section{ETHICS STATEMENT}

Written and informed consent was obtained from the parents of the patient for the publication of this case report. Patient also gave us assent to report her case.

\section{AUTHOR CONTRIBUTIONS}

KG has been reviewing the case, literature and drafting the work for publication. OG partially drafted the work and reviewed the literature. KN agreed to be accountable for all aspects of the work in ensuring that questions related to the accuracy or integrity of any part of the work are appropriately investigated and resolved. RC has helped drafting the work, obtaining the ophthalmic pictures via collaboration, and he provided approval for publication of the content. SB has helped drafting the work, obtained history from the patient and collaborators, and revised it critically for important intellectual content, and provide approval for publication of the content. HB contributed substantial to the conception and design of the work, or the acquisition, and analysis or interpretation of data for the work. She also agreed to be accountable for all aspects of the work in ensuring that questions related to the accuracy or integrity of any part of the work are appropriately investigated and resolved. All authors contributed to the article and approved the submitted version.

\section{REFERENCES}

1. Kwa MC, Silverberg JI, Ardalan K. Inpatient burden of juvenile dermatomyositis among children in the United states. Pediatr Rheumatol Online J. (2018) 16:70. doi: 10.1186/s12969-018-0286-1

2. Cassidy J, Petty R, Laxer R, Lindsley C. Juvenile Dermatomyositis. Textbook of Pediatric Rheumatology. Elsevier (2005). p. 40734. doi: 10.1016/B978-1-4160-0246-8.50024-3

3. Schwameis M, Schorgenhofer C, Assinger A, Steiner MM, Jilma B. VWF excess ADAMTS13 deficiency: a unifying pathomechanism linking 
inflammation to thrombosis in DIC, malaria. Thromb Haemost. (2014) 113:708-18. doi: 10.1160/TH14-09-0731

4. Malik ZR, Shahbaz A, Aziz K, Razaq Z, Umair M, Sachmechi I. Thrombotic thrombocytopenic purpura associated with dermatomyositis. Cureus. (2018) 10:e3161. doi: 10.7759/cureus.3161

5. Yamada S, Yamashita H, Nakano $M$, Hatano H, Sasaki T, Takahashi Y, et al. Thrombotic microangiopathy with polymyositis/dermatomyositis: three case reports and a literature review. Intern Med. (2018) 57:225965. doi: 10.2169/internalmedicine.0512-17

6. Saito Y, Hamamura K, Kurata Y, Sugimoto T. Case of dermatomyositis complicated by thrombotic thrombocytopenic purpura (TTP) which responded to combination of gamma globulin and vincristine-clinical analysis on TTP cases in the Japanese literatures. Jap Jour of Clin Hemat. (1993) 34:68-73.

7. Miyaoka Y, Urano Y, Nameda Y, Shigekiyo T, Horie T, Sano N, et al. A case of dermatomyositis complicated by thrombotic thrombocytopenic purpura. Dermatology. (1997) 194:68-71. doi: 10.1159/000246062

8. Shoda T, Kotani T, Takeuchi T, Makino S, Hanafusa T. A fulminant case of systemic sclerosis/dermatomyositis complicating thrombotic microangiopathy and diffuse alveolar hemorrhage. Nihon Kokyuki Gakkai Zasshi. (2009) 47:227-31.

9. Sawdyk MA, Jundt J. Dermatomyositis complicated by thrombotic thrombocytopenic purpura. Henry Ford Hosp Med J. (1985) 33:214-8.

10. Knox-Macaulay HHM, Adil SN, Ahmed EME. Acute thrombotic thrombocytopenic purpura following doxycycline treatment of chlamydia pneumonia infection in a patient with dermatomyositis. Clin Lab Haem. (2004) 26:147-51. doi: 10.1111/j.1365-2257.2004.00594.x

11. Bader-Meunier B, Monnet D, Barnerias C, Halphen I, Lambot-Juhan $\mathrm{K}$, Chalumeau $\mathrm{M}$, et al. Thrombotic microangiopathy and purtscher-like retinopathy as a rare presentation of juvenile dermatomyositis. Pediatrics. (2012) 129:821-4. doi: 10.1542/peds.2011-0338

12. Nuñez Zuno JA, Khaddour K. Thrombotic thrombocytopenic purpura evaluation and management. In: StatPearls. Treasure Island, FL: StatPearls Publishing (2020). Available online at: https://www.ncbi.nlm.nih.gov/books/ NBK470585/?report=reader\#_NBK470585_pubdet_
13. Moore J, Hayward C, Warkentin T, Kelton J. Decreased von Willebrand factor protease activity associated with thrombocytopenic disorders. Blood. (2001) 98:1842-6. doi: 10.1182/blood.V98.6.1842

14. Tsai HM. Pathophysiology of thrombotic thrombocytopenic purpura. Int $J$ Hematol. (2010) 91:1-19. doi: 10.1007/s12185-009-0476-1

15. Masias C, Cataland SR. Novel therapies in thrombotic thrombocytopenic purpura. Res Pract Thromb Haemost. (2017) 2:19-26. doi: 10.1002/rth2. 12066

16. Gürcan HM, Keskin DB, Stern JN, Nitzberg MA, Shekhani H, Ahmed AR. A review of the current use of rituximab in autoimmune diseases. Int Immunopharmacol. (2009) 9:10-25. doi: 10.1016/j.intimp.2008.10.004

17. Wiestner A, Cho HJ, Asch AS, Michelis MA, Zeller JA, Peerschke EIB, et al. Rituximab in the treatment of acquired factor VIII inhibitors. Blood. (2002) 100:3426-8. doi: 10.1182/blood-2002-03-0765

18. Emer JJ, Claire W. Rituximab: a review of dermatological applications. J Clin Aesthet Dermatol. (2009) 2:29-37.

19. Agrawal A, McKibbin MA. Purtscher's and purtscher-like retinopathies: a review. Surv Ophthalmol. (2006) 51:12936. doi: 10.1016/j.survophthal.2005.12.003

20. Yan Y, Xi S. Purtscher like retinopathy associated with dermatomyositis. $B M C$ Ophthalmol. (2013) 13:36. doi: 10.1186/1471-2415-13-36

21. Papadopoulou C, McCann LJ. The vasculopathy of juvenile dermatomyositis. Front Pediatr. (2018) 6:284. doi: 10.3389/fped.2018.00284

Conflict of Interest: The authors declare that the research was conducted in the absence of any commercial or financial relationships that could be construed as a potential conflict of interest.

Copyright (c) 2020 Gullapalli, Goldzweig, Nanda, Chekka, Berry and Bukulmez. This is an open-access article distributed under the terms of the Creative Commons Attribution License (CC BY). The use, distribution or reproduction in other forums is permitted, provided the original author(s) and the copyright owner(s) are credited and that the original publication in this journal is cited, in accordance with accepted academic practice. No use, distribution or reproduction is permitted which does not comply with these terms. 